\title{
PATHOS Y BATHOS EN EL GROTESCO \\ ESPECTÁCULO DEL MUNDO: \\ UN ANÁLISIS DEL TEATRO DE HILDA HILST
}

\author{
PATHOS AND BATHOS IN THE GROTESQUE \\ SPECTACLE OF THE WORLD: \\ AN ANALYSIS OF THE THEATRE OF HILDA HILST
}

\author{
Alva MARTÍNEZ TEIXEIRO \\ Universidade de Lisboa \\ alvamteixeiro@campus.ul.pt
}

Resumen: Este artículo pretende situar las obras de Hilda Hilst en el panorama de la dramaturgia brasileña del período de la dictadura, evaluando sus preferencias temáticas y procedimientos dramatúrgicos, dando especial énfasis a la importancia de lo grotesco. Además, este estudio analiza la originalidad de las obras dramáticas de Hilst, destacando la cautelosa distancia existente entre su filosofía estética y los elementos fundamentales de su universo literario —opresión, crueldad, alienación y obscenidad-y cualquier tendencia o etiqueta contemporánea.

Palabras clave: Grotesco. Teatro. Brasil. Hilda Hilst. Dictadura.

Abstract: This article intends to place Hida Hilst's plays in the panorama 
of Brazilian dramaturgy during the dictatorship period, evaluating thematic choices and dramaturgical procedures, with a strong focus on the importance of the grotesque. Also, this study analyses the originality of Hilst's dramatic works, noting the cautious distance of her aesthetic philosophies and the fundamental elements of her literary universe oppression, cruelty, alienation, obscenity - from any contemporary trends or labeling.

Key Words: Grotesque. Theatre. Brazil. Hilda Hilst. Dictatorship.

Il mondo esisteva prima dell'uomo ed esisterà dopo, e l'uomo è solo un'occasione che il mondo ha per organizzare alcune informazioni su se stesso.

(Italo Calvino)

\section{LA DRAMATURGIA HILSTIANA EN EL PANORAMA TEATRAL BRASILEÑO}

Después del intenso proceso de estudio y revaluación de su obra iniciado en los últimos años, la escritora brasileña Hilda Hilst (1930-2004), autora de más de cuarenta libros de poesía, teatro y prosa, es considerada una de las escritoras en lengua portuguesa más importantes del siglo XX.

La singular carrera de esta autora, que nunca se ajustó a ningún movimiento literario, se caracteriza por un trabajo culto y delicado, dedicado a expresar diferentes problemas filosóficos y morales, relacionados con los posibles lazos del hombre con la divinidad y la eternidad o con su opuesto, con el absurdo existencial y social contemporáneos.

A partir de 1967, iniciando una pausa en su producción poética, a la que había dedicado los quince primeros años de su carrera, Hilda Hilst escribió en tres años sus ocho piezas teatrales para, posteriormente, 
publicar, en 1970, su primera obra de ficción, de marcado carácter experimental. La razón de ese breve, pero intenso, contacto con el género teatral fue, según la autora, su deseo de establecer un contacto directo con el público, convirtiéndose en una de las autoras pioneras en el panorama teatral brasileño, en el que en la década de 1960 comenzaba a surgir un teatro escrito por mujeres, pues, como destaca Elsa Cunha de Vincenzo, las formas literarias silenciosas ya no eran suficientes y, al lado de la poesía y la ficción, comenzaba a aparecer el teatro, en una de las primeras acciones de las escritoras para apropiarse del espacio público (Vincenzo, 1992: 22).

Hilst confiaba en el poder expresivo de su obra teatral y en su capacidad para despertar al público brasileño y cambiar la situación del país, dominado desde 1964 por la dictadura militar. Su arma era un teatro de inspiración lírica que, gracias a la libertad del lenguaje poético y a un acertado uso de lo grotesco para reproducir de modo extrañado una época de crisis, podría revelar la hipocresía y la opresión típicas de los totalitarismos contemporáneos.

Así, la escritora escribe entre 1967 y 1968 las obras dramáticas $A$ empresa (La empresa), O rato no muro (El ratón en el muro), $O$ visitante (El visitante), Auto da barca de Camiri (Auto de la barca de Camiri), $O$ novo sistema (El nuevo sistema) y As aves da noite (Las aves de la noche) para, finalmente, en 1969, después del endurecimiento del régimen militar, crear $O$ verdugo (El verdugo) y A morte do Patriarca (La muerte del Patriarca), recibiendo la primera de esas dos piezas el premio Anchieta, uno de los más importantes de la dramaturgia brasileña del período.

Después de ese intento vehemente de comunicarse con el público de su país, parece que la autora paulista abandonó la escritura teatral, pero no la compleja visión de la condición humana presente en ella y en toda su obra literaria: trágica, pesimista y, frecuentemente, dominada por un poderoso sentimiento de extrañeza e inconformismo ante la falta de sentido de la existencia humana en todas sus dimensiones.

Probablemente, la autora, profundamente sensible a la recepción minoritaria de su compleja obra literaria - fue tachada por algunos críticos 
de megalómana por sus polémicas actitudes y declaraciones públicas-, decidió abandonar la escritura dramática movida por el desengaño que le provocó la insuficiente atención del teatro profesional brasileño que, en aquel período difícil, dio prioridad a los textos más explícitamente comprometidos, secundarizando la propuesta hilstiana que, en esa época, fue objeto de un número menor de representaciones, aunque sobresalientes.

Como señala el profesor Décio de Almeida Prado, las circunstancias históricas determinaron las preferencias de la comunidad teatral. Esta, durante los años anteriores y posteriores al advenimiento de la dictadura, dominada por las facciones más "combativas", se reconoció en la dramaturgia abiertamente política, aún más que en la social (Prado, 2001: 97), a pesar de la fuerte censura dominante en el país desde la anterior dictadura, el denominado Estado Novo (1937-1945), que intentó controlar la actividad teatral del movimiento nacionalista y vanguardista surgido en la década de 1920 e influenciado por la vanguardia europea, importada por los numerosos artistas extranjeros que llegaron a Brasil huyendo de la persecución política y/o religiosa sufrida en Europa:

[...] the theatre was censored and restrained in this long period, even in the years of democracy (1946-1963), so that the authors who did the national theatre during the period had their artistic production hard pursued and restricted by censors. The justification for this persecution is that censorship, after the Estado Novo of Vargas, began to be made by a state bureaucratic apparatus constituted and dedicated to surveillance of theatrical artistic production. This mecanism was not dismantled in the following decades. On the contrary, both the democratic and military governments that took power in 1964 used it. If in the periods of excepcion, the major focus of the censors was against the political orientation of the pieces, in less difficult times the most censored themes were of moral, religious and social background (Costa y Sousa Júnior, 2018: 63). 
Sorprendentemente, pese a la inusual estabilidad, raigambre y eficiencia de la censura en el país latinoamericano, el teatro brechtiano fue el que dominó gran parte de las estéticas dramatúrgicas — principalmente, de las preferidas por el teatro profesional - en la segunda mitad del siglo. La lucha de clases presente, por ejemplo, en Revolução na América do Sul (Revolución en América del Sur, 1960) de Augusto Boal o en Gota d'água (Gota de agua, 1975) de Chico Buarque y Paulo Pontes, así como la transfiguración del contexto político-social en esta última, se oscurecen y se distancian radicalmente de la realidad en la obra hilstiana a través de la sublimación y, con frecuencia, de su opuesto, lo grotesco: en esta, la profunda humanidad de los protagonistas es elevada y transmutada en verdad ontológica y social, mientras que los antagonistas son reducidos a portavoces de la alienación y la crueldad.

El teatro hilstiano es, por lo tanto, singular en el campo teatral brasileño, tanto en relación con la matriz épica brechtiana, como con la vertiente realista que caracterizaba, entre otras, la producción teatral de la emergente dramaturgia escrita por mujeres. De hecho, el de Hilst es un teatro simbólico, intelectual y más violento, con un universo dramático concebido como oposición entre las dos fuerzas que para la autora dominarían la realidad: el principio de autoridad y el principio de libertad. En casi todas sus obras la escritora situó en primer plano los que para ella eran las dos grandes propuestas modernas en defensa de la igualdad y la justicia: el cristianismo y el progresismo, ambas frustradas por el fanatismo, representado, con frecuencia, de modo notablemente grotesco. En la mayoría de las obras de Hilst, el hombre de la Iglesia se convierte en un puritano dominado por la compulsión de reprimir y castigar. Su opuesto, el hombre del Progreso, es retratado como un represor maquiavélico que oculta, bajo el aparente compromiso civilizador, un impulso catequizador inflexible. 


\section{LA PRESENCIA DE LO GROTESCO EN EL TEATRO HILSTIANO}

De acuerdo con lo dicho anteriormente, en este artículo, pretendemos estudiar el arte subversivo de Hilda Hilst, centrándonos en el análisis de las obras en las cuales la presencia de lo grotesco es central, es decir, Auto da barca de Camiri, O novo sistema, As aves da noite y $A$ morte do Patriarca, y realizando, de modo complementario, incursiones puntuales en otras piezas, pues cierta deformación grotesca está presente en todas ellas con la misma finalidad, la sátira de los sistemas totalitarios.

Se trata, por lo tanto, de un grotesco utópico, pues "es puesto en circulación por ser partidario del avance democrático de los derechos sociales: con un discurso liberatorio pone en cuestión determinadas convenciones y ofrece al público una reflexión sobre otros mundos posibles" (García-Pascual, 2012: 15), pero no de un grotesco solar o jocoso, pues en él nunca predomina la risa festiva. La primera pieza de la autora donde lo grotesco es relevante, Auto da barca de Camiri, se orienta hacia el ámbito de la carnavalización, pero, posteriormente, las otras obras divergen, optando por el humorismo trágico, no carnavalesco, donde ciertos elementos grotescos subrayan la abyección y el absurdo imperante, existiendo, de hecho, ciertos paralelismos, con el teatro de la crueldad artaudiano.

De todos modos, a pesar de esa diferencia, incluso esa primera obra referida es, como las otras, notablemente trágica, pues como fue indicado por Jan Kott, “le grotesque adopte les schémas dramatiques de la tragedie et pose les mêmes questions fondamentales " (Kott, 1978: 119), variando apenas en todas ellas, como veremos, la diferente intensidad de lo grotesco y del uso de algunas de sus técnicas y elementos, como el sarcasmo, la hiperbolización, la corporeización, la deshumanización, la reificación, la desrealización escénica o lo escatológico. 


\subsection{La sátira carnavalesca del Auto da barca de Camiri}

Auto da barca de Camiri es la obra en la cual el retrato simbólico de la realidad está más claramente dominado por la irreverencia de la farsa y del "principio de deformación", esencial en lo grotesco (Pavis, 1998: 247), en detrimento de un lirismo metafísico evocado secundariamente por el protagonista in absentia, el Che Guevara.

En la obra, el trágico capítulo de la Historia de América Latina protagonizado por el revolucionario asesinado es el punto de partida de una sátira que se proyecta hacia lo universal y en la cual lo grotesco, por inhumano, se filia a lo escatológico.

En realidad, la única referencia (alusiva) a la muerte del insurgente argentino es el topónimo Camirí, presente en el título, pues el comandante nunca es llamado por su nombre. En la obra él es el Hombre, uno de los diversos representantes en el teatro hilstiano del héroe sacrificado y caracterizado por un aura casi religiosa, evocando la inequívoca concepción que tiene la autora de la revolución: una manifestación pura de la humanidad cuyo resultado sería la proclamación de la hermandad entre los hombres.

La acción dramática se inicia así in media res, con el protagonista ya ausente de un juicio que, una vez muerto ese posible redentor, tiene como objetivo confirmar y atestar que, en realidad, ese hombre asesinado nunca existió. Cabe señalar que la clasificación de la pieza como auto evoca dos posibles filiaciones respecto del género dramático medieval y renacentista e, igualmente, respecto del juzgamiento kafkiano: ambos modelos coexisten en esta obra en la cual, si el motor de la acción carece de sentido y evoca la inaccesibilidad de la ley, también permite una lectura moralizadora de los abusos de la autoridad, simbolizando el mal que, para mantener el poder, es capaz de falsificar la Historia.

En este sentido, para hacer patente la naturaleza despropositada y deforme de la omnipotencia de los representantes de la ley, el espacio en que tiene lugar el juicio es severo, estando dominado por "símbolos 
enormes de justiça" (Hilst, 2008: 185), como la puerta por la cual entran los jueces, "rebuscada, grotesca" (Hilst, 2008: 185), en contraposición con la pequeña puerta destinada a los testigos.

Ese contraste caricaturesco se ve además reforzado gracias a una llamada de atención sobre la materialidad del cuerpo de los jueces, que sirve a Hilst para rebajar hasta la abyección el principio consagrado de la justicia, pues a pesar de que las didascalias informan de que los miembros del tribunal se mantienen "formalíssimos" (Hilst, 2008: 196), son sorprendidos por el primer testigo que entra en la sala en calzones. Los jueces, viendo peligrar el poder que les confiere, no su moral o su equidad, sino la ritualidad a la que se ve reducido el sistema legal abusivo que representan, piden al testigo, alarmados, que abandone la sala, a lo que ese testigo, el Trapecista, responde que la situación embarazosa no tiene importancia, porque los jueces siempre serán jueces: "Da matriz (aponta o sexo) / à morte"1 (Hilst, 2008: 193).

En una técnica de contraste, en oposición al ascetismo del protagonista in absentia - un fallido redentor-y de sus defensores - el Prelado, el Trapecista o el Pajarero, que de un modo u otro representan una vida orientada también hacia las alturas_-, desde el principio es destacada la importancia excepcional que tiene en el comportamiento y el pensamiento de los dos jueces lo material y lo corporal. Además de esa fugaz imagen asociada a la sexualidad, ambos basan su modo de proceder en la corte en una premisa, la de que los testigos son siempre infectos (Hilst, 2008: 189), una idea que dominará la representación, pues en una de las didascalias la autora advierte que, durante la obra, los jueces deben mostrar el desagrado que les provocan los testigos tapándose la boca con un pañuelo. Esa visión de la repulsa provocada por el pueblo, menospreciado, es reforzada por uno de los diálogos mantenido entre los jueces, fuertemente marcado por

\footnotetext{
1"Desde la matriz (señala el sexo) / hasta la muerte". Como en esta ocasión, a lo largo de estas páginas, a fin de facilitar la lectura, traduciremos libremente y respetando las peculiaridades estilísticas y rarezas expresivas de la autora, los fragmentos citados de las piezas teatrales de Hilda Hilst.
} 
la metateatralidad y en el que, no sin cierta ironía, el Juez Joven y el Juez Viejo hablan sobre la naturaleza escatológica de la contemporaneidad y, por consiguiente, del necesario carácter escatológico del arte dirigido al público contemporáneo:

JUIZ JOVEM: Tem razão. Tem razão. Os homens são seres escatológicos. Esse tema é ótimo para discorrer. Veja (vira-se para a platéia) Escatologia, certamente os senhores saberão o que é: nossas duas ou três ou mais porções matinais expelidas naquilo que quase sempre convencionalmente chamamos de bacia. Enfim (curva a mão em direção à boca e estende em direção ao traseiro), esse entra e sai. Para vencer o ócio dos senhores, que dia a dia é mais freqüente, não bastará falar sobre o poder, a conduta social [...]. É preciso um outro prato para o vosso paladar tão delicado. (vira-se para o velho) E se pensássemos num tratado de escatologia comparada? Nada mais atual e mais premente.

JUIZ VELHO: Comparada com o quê?

JUIZ JOVEM: Com tudo! Com tudo!

JUIZ VELHO: Ah, talvez bem pensado porque...

JUIZ JOVEM: Porque tudo o que se compara, se entende. E se transforma em conflito sempre eminente.

JUIZ VELHO: Tudo isso é bom para o teatro. Fale merda para o povo e seja sempre novo ${ }^{2}$ (Hilst, 2008: 189).

\footnotetext{
2“Juez Joven: Tiene razón. Tiene razón. Los hombres son seres escatológicos. Ese tema es perfecto para discutir. Mire (se gira hacia la platea) Escatología, seguramente los señores sabrán lo que es: nuestras dos o tres o más porciones matinales expulsadas en aquello que casi siempre convencionalmente llamamos palangana. En fin (curva la mano en dirección a la boca y la extiende en dirección al trasero), ese entrar y salir. Para vencer su ocio, que día a día se vuelve más frecuente, no bastará hablar sobre el poder, la conducta social [...]. Es necesario otro plato para un paladar tan delicado como el suyo. (se gira hacia el viejo) ¿Y si pensásemos en un tratado de escatología comparada? Nada más actual y más urgente.

Juez VIEJo: ¿Con qué se compararía?
} 
De acuerdo con los jueces, la escatología sería la única realidad comprensible e interesante para una colectividad que, según su visión maniquea del mundo, se caracterizaría por su atrofia y estupidez. Siguiendo un raciocinio basado en el antagonismo necesario, esta concepción reaccionaria, revela, como en muchos otros personajes grotescos, una conciencia muy deficiente del Otro y del mundo circundante como entidad y espacio tendentes a la diferencia (Mariano, 2005: 61). La autora, por lo tanto, hace que sus protagonistas razonen, moralicen y expliciten los valores funestamente universalizantes de este episodio histórico deformado gracias a un lúcido e irreverente recurso a lo grotesco, que ilumina la tensión que inspira la obra, la lucha entre dos planos escatológicos que, a pesar de la homonimia, son claramente diferenciados gracias a las aclaraciones del Juez Viejo: “um, é essa tua matéria, está certo. O outro, faz parte da teologia. Escatologia: doutrina das coisas que deverão acontecer no fim do mundo" (Hilst, 2008: 191).

Así, por intermedio de lo grotesco y lo disforme del imaginario escatológico, Hilst revela la tensión que sacude los cimientos de la contemporaneidad: la tensión entre la elevación y la grandeza de la fraternidad y la bajeza de la alienación que los jueces atribuyen el pueblo, pero que, en realidad, es una proyección de la indiferencia del cesarismo que ellos representan, cesarismo del que son emblemas su carnalidad y materialismo.

Se trataría, en lógica consecuencia, de un perfecto ejemplo de cómo las distorsiones grotescas pueden ser útiles "en calidad de pervertida literatura edificante" (Kayser, 2010: 220) en el grotesco moderno estudiado por Wolfgang Kayser, quien, como Hilst, comprendía vida y

Juez Joven: ¡Con todo! ¡Con todo!

JueZ VIEJO: Ah, tal vez esté bien pensado porque...

Juez Joven: Porque todo lo que se compara, se entiende. Y se transforma en conflicto siempre inminente.

Juez VIEJo: Todo eso es bueno para el teatro. Dígale mierda al pueblo y sea siempre novedoso". 
muerte como separadas; razón por la cual, a pesar de las críticas de Bajtín a Kayser, nos serviremos ad hoc de propuestas e ideas de ambos, con el fin de comprender mejor la compleja y heterogénea propuesta de la autora brasileña. En fin, se trata de una propiedad, la edificación, que, para existir, necesita que la deformación metamórfica y desintegradora no sea extrema, para que el modelo referencial, previo al desvío subversivo, sea fácilmente identificable por el espectador, pues, parafraseando la afirmación realizada por Umberto Eco en su Segundo diario íntimo, para que la transgresión tenga éxito es necesario que se perfile sobre un fondo de normalidad.

De este modo, el sentido común es representado por los personajestestigos, que son los únicos que desean demostrar la existencia del Hombre, contradiciendo el propósito del tribunal y las absurdas objeciones presentadas por otro de los testigos. De su mano, nos adentramos en el grotesco mundo del juicio, dominado por discursos que buscan la risa carnavalesca a partir de asuntos terribles, fácilmente reconocibles por el público, por ser universales, como la intransigencia, demostrada por los jueces, que obligan a los testigos a demostrar la existencia de su redentor de modo empírico.

Se trata de un episodio muy similar al protagonizado por los miembros de otro tribunal, en este caso religioso que, en una pieza anterior, A empresa, piden a una joven reformadora, América, que demuestre en una pizarra la existencia del Dios en el que ella cree, diferente de aquel que ellos adoran. Deidad que es retratada por la autora a través de una retórica del sacrificio notablemente grotesca, condensada en la historia, numerosas veces relatada por los religiosos, de una santa que besaba las heridas de los leprosos. Para América esa concepción de la religión es demencial, repulsiva y macabra, porque sus creencias son radicalmente divergentes: para ella, Dios era un hombre honesto, caracterizado por el Amor al prójimo y no por la morbidez.

En fin, como los declarantes del Auto da barca de Camiri, América es obligada a intentar probar sus certezas con relación a la existencia de ese Dios humanitario y elevado que, como el Hombre, el tribunal prefiere 
considerar imposible e irreal. Esto es así porque los representantes del poder solamente aceptan y comprenden lo material, como explicita expresamente la fe ciega en la Técnica del Inquisidor, uno de los miembros del tribunal de $A$ empresa. Una ofuscada creencia que se demuestra con la ecuación "trabalhar para comer, comer para trabalhar" (Hilst, 2008: 84) que pretende resumir la vida utilitaria y embrutecida deseada para su rebaño, sirviéndose de un diktat que, de cierto modo, anticipa la visión escatológica del pueblo presentada por el Juez Joven del Auto da barca de Camiri.

Nos situamos, por lo tanto, ante un discurso que es reflejo de un pensamiento basado en una concepción deformada del racionalismo y del pragmatismo contemporáneos, una lógica que se exacerba en el raciocinio de otro de los testigos, significativamente, el único que, según los jueces, es decente y no huele, el agente funerario que vive de la muerte ajena. El pensamiento de este personaje refleja el paroxismo de la moralidad invertida que domina las obras y que, como mecanismo distópico, se orienta hacia lo grotesco gracias al utilitarismo nonsense que defiende durante el juicio. Cuando el Pajarero relata, como muestra de la existencia y trascendencia del Hombre, que este había resucitado un pájaro, el Agente niega vehementemente esa prueba, no porque tema el virtuosismo revolucionario del Hombre, materializado en ese pequeño milagro, sino porque la resurrección disminuiría su negocio de venta de ataúdes.

Hilst nos sitúa así ante una degradación de lo sublime, materializada en la exposición del Agente, en el cual lo alto y lo bajo se confunden, en el sentido apuntado por Bajtín para la parodia moderna, donde la "ambivalencia regeneradora" de la degradación es sustituida por "un carácter exclusivamente negativo" (Bajtín, 2002: 26).

Así, el razonamiento del Agente es dominado por el principio del absurdo desarrollado con una lógica paradójica, consistente en partir de una premisa absurda y desarrollar un raciocinio perfectamente congruente, organizado en una gradatio, en el que, finalmente, el personaje, que vigila al Trapecista, esperando que muera cuando da saltos altos, propone a los 
jueces que todo aquel que muera, sea hombre o pájaro, de modo definitivo o no, deba comprar un ataud (Hilst, 2008: 208).

En esta distorsión tragicómica de la realidad, los personajes de los Jueces y del Agente evocan dos de los elementos paradójicos de la naturaleza humana, propios de lo grotesco: una primera contradicción, lógica, que nos lleva al ridículo, al afirmar que los hombres racionales son irracionales - como demuestran los jueces al exigir, como requisito para admitir su existencia, una prueba empírica de la realidad de un hombre que, por su condición de líder, formaba parte activa y visible de la sociedad-, mientras que el horror surge de una segunda contradicción, ética (Meindl, 1996: 15), presente en la consideración de que los hombres son inhumanos, como demuestra la violencia del sistema con el Hombre o la ambición desmedida del Agente.

En ese grotesco tiempo de desamor y lamento (Hilst, 2008: 187) del que nos habla el Trapecista - que observa los acontecimientos y el mundo desde lo alto, como el gimnasta de Kafka— todavía existen razones para la esperanza, porque, aunque no apoye activamente la defensa del Hombre, en un primer momento, la actitud crítica del pueblo contradice la imagen que los jueces tienen de él. La irrupción del pueblo con sus cantos en el paisaje apocalíptico de la tiranía del pragmatismo despótico, miniaturizado en el juicio, parece evocar lo carnavalesco, pues a pesar de no tratarse propiamente de una celebración del Carnaval, los cantos del coro popular, colectivo y genérico traen a la imaginación la abolición provisional de las relaciones jerárquicas, permitiendo la libre expresión de opiniones discordantes característica de esa desatada festividad. A pesar del disgusto que la entrada impetuosa del pueblo en la sala provoca en los jueces que, nuevamente, se tapan la nariz, en apariencia, el contacto es más libre, pues, pese a que las jerarquías se mantienen, el pueblo, transgresor, osa decir lo que piensa:

\section{Ai, coisa complicada}

São os da cidade 


\section{Os que vêm dizer}

Se o homem que a gente vê

É de verdade ou não (Hilst, 2008: 194).

La influencia de la cosmovisión carnavalesca, por lo tanto, evoca aquí la noción de la discursividad dialógica teorizada con relación a lo grotesco por Bajtín. En ese momento en que el tribunal se convierte en la plaza pública, el pueblo-coro, explicita en su primera intervención su visión crítica de los eventos para, después, en la segunda canción interpretada en la corte, poner de manifiesto la consciencia del papel que le cabe en ese mundo al revés, farsesco, un papel, dicho sea de paso, que no sabemos si acepta o no:

Homem que a gente vê

Mas ninguém quer

Que se veja

Ai, chupa o meu mindinho

E assim tu me distrai

E eu não vejo nada

Além do meu mundinho (Hilst, 2008: 194).

Esta nueva intervención del pueblo constituye un perfecto ejemplo de la tendencia notable de lo grotesco hacia la entropía (Mariano, 2005: 60) y un evidente paradigma de cómo, por causa de esta especial capacidad perceptiva, esta categoría "is fundamentally allied to becoming, to motion as opposed to being” (Meindl, 2005: 9). Así, no sabemos si en la miniatura de esa época ignorante y oscura -materializada en la vulgaridad del lenguaje del pueblo- que Hilst nos presenta en esta obra observamos el retrato de un pueblo irónicamente crítico o un retrato formado apenas por contorsiones y movimientos de títeres; dicho de otro modo, no somos capaces de discernir si el personaje colectivo es reducido ya a una sombra o silueta de fácil manipulación, como sucederá, de hecho, en otras obras de 
la autora, en que la representación del pueblo se oscurece, oscilando entre la alienación y la crueldad.

En este reverso delirante de la realidad, la autora utiliza la risa para provocar al espectador, situándolo dentro de los márgenes de la convivencia perturbadora del humor y la tragedia que caracteriza lo grotesco:

The grotesque emerges as a contradiction between attractive and repulsive elements, of comic and tragic aspects, of ludicrous and horrifying features. Emphasis can be placed on either its bright or its dark side. However, it does not seem to exist without a certain collision between playfulness and seriousness, fun and dread, humour and horror, glee and gloom (Meindl, 2005: 7).

Así, la escena carnavalesca es sofocada por la violencia del sistema: durante buena parte de la obra, el ruido de metralletas y revólveres ratifica las intervenciones de los jueces sobre la Ley, hasta que, finalmente, esos mismos disparos ponen fin a la invasión del pueblo y a su testimonio subversivo. Así, aunque el Juez viejo hable del hedor de los testigos (Hilst, 2008: 189), son los representantes de la autoridad los que son más claramente dominados por la escatología mundana.

Como indica Patrice Pavis, "al igual que la distanciación, lo grotesco no es un simple efecto de estilo, sino que compromete toda la comprensión del espectáculo" (Pavis, 1998: 247), permitiéndonos entender mejor, gracias a la tendencia estructural a la deformación, cómo, en ese mundo deformado, reflejo del nuestro, la escatología teológica es asfixiada y acallada por una escatología corporal. Un conjunto de creencias que alcanza su punto álgido con la matanza de los declarantes y con la simbólica moción de los jueces para, resuelto el problema, ir a comer, en una propuesta que, como otras referencias similares, es una grotesca metáfora de las relaciones de depredación que dominan la dramaturgia hilstiana. 


\subsection{Las tenebrosas distopías de $A$ s aves da noite, $O$ verdugo, $O$ novo sistema y A morte do Patriarca}

Si, como afirmó Genette, lo cómico es lo trágico visto de espaldas, según este principio, podemos comprender algunas de las imágenes asociadas a la comida y a la satisfacción de otras necesidades básicas del ser humano, presentes en obras como As aves da noite, $O$ verdugo, $O$ novo sistema o A morte do Patriarca, en las que la representación de la naturaleza escatológica del hombre social adquiere contornos tenebrosos.

2.2.1. El retrato del nazismo y la experiencia de lo abyecto en As aves da noite

De esta manera, la siguiente distopía teatral concebida por Hilst se basa en el terrible espectáculo mortífero del nazismo, a través del cual la autora llega a la abyección más absoluta. A obra As aves da noite representa la tentativa más radical de la dramaturga paulista en su empeño por examinar el lado más oscuro de la naturaleza humana, abordando el problema de la falta de humanidad de ciertos seres (humanos) para presentar a su público una perturbadora, pero completa, imagen del hombre.

En esta pieza, la imagen de las aves de la noche evoca la siniestra figura de los guardias de las SS que vigilaban las celdas de Auschwitz. Como la autora explica en una nota inicial, la obra se inspira en un hecho real, ocurrido en 1941 en aquel tristemente famoso campo de concentración, donde, como castigo por una fuga de presos, los guardias escogen, de modo arbitrario, a cinco prisioneros para que expíen las culpas de cinco fugitivos, encerrándolos en el denominado Sótano del Hambre, una celda donde agonizarían por efecto de la inanición hasta la muerte. Ante la desesperación de uno de los presos elegidos, el padre franciscano Maximilian Kolbe se ofrece para sustituirlo, siendo encarcelado con los otros presos hasta la muerte. 
Así, la autora concentra en un espacio claustrofóbico aquello que consideramos imposible, intolerable, inconcebible: la representación de las últimas horas de tortura y sufrimiento de los cinco condenados permite a Hilst, por un lado, reflexionar sobre la naturaleza del mal o sobre la existencia de Dios y, por otro lado, enfrentarnos a lo abyecto, a través de los discursos de esos agónicos protagonistas, principalmente de las reflexiones del padre franciscano.

Cuando la obra comienza, los condenados llevan ya algún tiempo en la celda y, por lo tanto, se nos muestran rebajados a una condición animalesca, pues, una vez superado el límite de la resistencia humana, solo resta el desespero o la santidad (Hilst, 2008: 235). En esa situación extrema, uno de los prisioneros, el Estudiante, proclama que el hombre es voraz, una afirmación de una realidad que si es asumida por el hombre en este caso, por el público de la obra teatral — lo aniquila y, ante la cual, la idea de la abyección funcionaría como un salvavidas (Kristeva, 1982: 2).

Un auxilio que la dramaturga — auténtica traumaturga - nos quiere negar, insistiendo, sin lenitivos, en la idea de la atrocidad humana, resumida en la idea de que Hitler —única figura histórica explícitamente referida en todo el teatro de Hilst - es la otra cara de cada uno de nosotros (Hilst, 2008: 279). La obra de Hilda Hilst, una autora traumatizada por la vileza humana, sería, en consecuencia, un instrumento privilegiado de representación de las crisis y de los más íntimos y más serios apocalipsis del ser humano contemporáneo, como fue señalado por Julia Kristeva respecto a las obras de autores poseídos por la abyección (1982: 208).

En este sentido, en una entrevista concedida en 1977 a un importante periódico de su país, el Estado de São Paulo, y parcialmente reproducida en el estudio Um teatro da mulher, la escritora brasileña significativamente afirmaba:

Eu lido com situações limites do homem, o que implica explorar todas as grandezas e debilidades, seguranças e dúvidas. É como se o que sempre se trata como 'espirito'no abstrato — reverenciado 
a distância ou menosprezado no imaterial - ganhasse um corpo com vísceras. É aí que eu quero perscrutar éé, para mim, uma busca apaixonante que se traduz numa linguagem ${ }^{3}$ (Vincenzo, 1992: 44).

Como prueba de ello, la atrocidad de los guardias de las SS es compartida por un personaje diferente, un personaje problemático desde el punto de vista moral, la Mujer. Se trata de una de las presas encargadas de la limpieza de las cámaras de gas que confiesa a los prisioneros y al público que, cada vez que cumple su tarea, siente una inmensa alegría por no ser ella uno de los muertos de lo que denomina una matanza (Hilst, 2008: 277), que describe como una pirámide de sangre: "eles estão junto à porta de metal, como uma pirâmide toda feita de sangue, de sangue muito escuro" (Hilst, 2008: 266).

A pesar de que el franciscano intenta convencerla de que es un ser humano igual a los demás, pues las ganas de vivir son muy fuertes y cualquiera haría lo mismo en su lugar, el Carcelero, uno de los SS, se pregunta cómo esa mujer puede vivir y comer después de participar regularmente en ese espectáculo apocalíptico, provocando su desesperación y motivando que suplique por su salvación, mientras reconoce el asco que siente de sí misma.

En este sentido, es de destacar el predominio excepcional que tienen en la obra la corporalidad y la materialidad, asociadas, no a la vida, sino a la agonía y a la supervivencia, a través de las imágenes hipertrofiadas de los cuerpos y de la satisfacción de las necesidades alimenticias y sexuales, aniquilando el inestable equilibrio entre lo risible y lo trágico presente en la obra anterior. Esa exacerbación de lo trágico grotesco es subrayada por el fortísimo contraste existente entre esa corporalidad atroz y el ascetismo

\footnotetext{
3"Yo me enfrento a las situaciones límite del hombre, lo que implica investigar todas las grandezas y debilidades, certezas y dudas. Es como si aquello que siempre se trata de modo abstracto como 'espíritu' — venerado a distancia o despreciado por inmaterialadquiriese un cuerpo con vísceras. Es ahí donde quiero indagar y es, para mí, una búsqueda apasionante que se traduce en un lenguaje".
} 
y la calma del protagonista, el padre Maximilian, incomprensible para los demás personajes, que, significativamente, se preguntan si él es un hombre hecho de carne (Hilst, 2008: 247).

Frente a la experiencia de penitencia contemplativa del protagonista, las imágenes de grotesca dureza de la muerte y de la, aún más trágica, vida en el campo de concentración y en las cámaras de gas parecen dialogar con las obras de otros artistas que, como la autora brasileña, sintieron la necesidad de expresar su visión sobre el Horror contemporáneo a través del arte. Desde este punto de vista, el carácter obscenamente grotesco de la escena de la Mujer comiendo, inmediatamente después de abandonar el paisaje dantesco de las cámaras del horror, puede ser iluminado por la evocación de los grabados de la serie La guerra de Otto Dix, que plasman su experiencia durante la I Guerra Mundial. Marcados por un provocador culto al horror, entre los dibujos de esa serie del pintor expresionista alemán, podemos encontrar, igualmente, la abyección representada por el retrato de personas que, como la Mujer, comen al lado de los muertos.

Como Dix, Hilst se sirve de diversos recursos de la construcción acumulativa de lo grotesco para presentar al púbico una miniatura del paisaje desolador de una humanidad inhumana, cuya vida se limita a la más terrible supervivencia; de tal manera que la presencia de lo grotesco corporal ocupa todo el espacio en la obra, inclusive las acotaciones, en las que la autora indica:

Fora ouvem-se vozes de vários SS. Deve ficar claro para o público que estão estuprando uma mulher que está morrendo. Frases assim, por exemplo:

- assim, segura mais firme

- abre mais

— a cadela não abre [...] (Hilst, 2008: 286).

El público, los potenciales espectadores de la obra, son abandonados ante la pura experiencia de la atrocidad representada por estas imágenes, 
sin lenitivos, sin retóricas y sin explicaciones, pues, como era mostrado, pero de modo diverso, en el Auto da barca de Camiri, "el artista grotesco no puede ni debe procurar un sentido a sus creaciones, porque tampoco le está permitido desviarnos del absurdo" (Kayser, 2010: 312). En este sentido, también la experiencia de inmersión en ese mundo deforme y sin sentido es radical en todos los sentidos posibles, pues, como el Carcelero le dice al padre franciscano, "aqui você já é a morte, tudo que você fala é a morte que fala" (Hilst, 2008: 257). Y, en efecto, todo es sofocado por la muerte, hasta la grotesca imagen de Dios, oscilante entre un Dios muerto y un Dios perverso y masoquista. Se trata de un Dios que, según uno de los condenados, duerme un sueño tan profundo que ya tiene unos párpados rígidos que nunca más se abrirán, o de un Dios que, según el Carcelero, si escoge para sí mismo el martirio, tiene que ser un ser insaciable, para el que ningún sacrificio será suficiente (Hilst, 2008: 277).

En ese mundo, del cual hasta los dioses han desertado, aquellos que detentan el poder se inspiran en lo demoníaco, disfrutando del sufrimiento y la aniquilación de los opositores, como demuestra la grotesca jocosidad de uno de los guardianes de la celda de la muerte que, ante el sacrificio voluntario del franciscano, después de calificar el gesto como conmovedor y de reírse, le ofrece al protagonista una corona de alambre de espino.

\subsubsection{La miniatura futurista del totalitarismo de $\mathrm{O}$ novo sistema}

El paroxismo de ese horror, de esa terribilità ridículamente extravagante está presente, igualmente, en la pieza $O$ novo sistema, que retrata el mal a través de otra grotesca alegoría de la contemporaneidad, en este caso, una alienante distopía de inspiración futurista. Esta vez, el conflicto es provocado por el hecho de aun existir en la nueva sociedad ciudadanos inadaptados al sistema totalitario vigente, basado en el Progreso y el culto a la ciencia, como el Niño, el protagonista de la obra: un niño inteligente, sensible e inocente que pasea por las calles de la ciudad con su madre, cuestionando insistentemente lo que ve a su alrededor. 
Los paralelismos con la pieza anterior son notables, pues en $O$ novo sistema nos encontramos de nuevo con la represión filtrada a través de lo grotesco, ya que otro subalterno del sistema, el Escudero-Mayor, acepta por parecerle muy graciosa la propuesta- que las madres de los líderes del Viejo Sistema, juzgados y condenados por la nueva dictadura, les hagan unas alas a sus hijos para que, como reconocimiento de su sufrimiento, las lleven en el camino hacia la ejecución. La oscura razón de esa inesperada concesión acaba revelándose cuando sabemos que las ancianas madres son condenadas hasta la muerte a matar pájaros para hacer las alas, dado el elevadísimo número de ejecuciones de opositores, ejecuciones que se convierten en un exterminio y que, a su vez, provocan que casi ya no haya pájaros y que las ancianas estén medio ciegas (Hilst, 2008: 341).

La autora destaca, así, la naturaleza apocalíptica de unos tiempos "inquietantes" (Hilst, 2008: 324), representados también en esta obra, en la cual, ni el Escudero-Mayor calculaba las dimensiones futuras del genocidio, incipiente al principio de la acción. En este sentido, en cierto momento de la pieza teatral, otro de los escuderos afirma que los enemigos del régimen ajusticiados son tantos como hormigas (Hilst, 2008: 324). Se trata de una grotesca animalización que será extremada a través de la cosificación de los muertos presente en algunos de los hechos mencionados por los personajes, dado que el depósito de cadáveres, aun habiendo triplicado sus servicios, no tenía espacio suficiente para todos los cadáveres, viéndose obligados los escuderos a atar a los muertos en las plazas, sustituyéndolos constantemente por nuevos ejecutados.

En una nueva variación del tema de la espiritualidad mutilada por el poder, entre esos seres cosificados, reducidos a meros bultos, a carne muerta y a espectáculo por el sistema, la autora destaca la presencia de los cadáveres de dos religiosos, un padre y un obispo, pues, según explica uno de los escuderos, las ejecuciones de hombres de la Iglesia son constantes. De este modo, a través del grotesco contraste entre cuerpo y espíritu, la autora examina dramáticamente la terrible experiencia contemporánea de la exclusión y de las heroicas tentativas de transgresión que algunos 
personajes protagonizan, pues, a pesar del totalitarismo, siempre hay espacio para la transgresión, como indica Michel Foucault: "au moment oú il marquent le limite, ils ouvrent l'espace d'une transgression toujours possible" (1994: 624).

De todos modos, pese al valor y la osadía de esos personajes, el retrato negativo impera en escena, también por la crueldad demostrada por el pueblo que, con su mórbida fascinación por las ejecuciones, reforzaría la idea de que el mal está presente en el lado oscuro y latente de todos nosotros: uno de los personajes afirma que se trata de un ritual de alegría para la nación y que los ciudadanos que deseen asistir al espectáculo deben reservar un sitio con antelación, lo que nos da una (paradigmática) idea del gran interés generado.

Una vez más, el retrato del pueblo no es nítidamente positivo, pero aun así no se iguala nunca al de los antagonistas, los poderosos o sus subalternos, caracterizados por su perversidad, pues la masa se distingue todavía por su alienación, una alienación que en las últimas obras se transformará en auténtica y estremecedora brutalidad.

\subsubsection{La conclusión iconoclasta de la distopía hilstiana en $\mathrm{O}$ verdugo $y$ A morte do Patriarca}

La revelación de la animalidad humana ya anunciada por la importancia que, en las figuraciones de lo grotesco presentes en las obras, adquirían ciertas necesidades básicas, en especial, la alimentación, continúa e incluso se exacerba en obras como $O$ verdugo o A morte do Patriarca. En estas dos propuestas dramáticas, las alusiones a la plaza pública, a lo escatológico y a lo lascivo intensifican y oscurecen su simbolismo, como imágenes, ya no de la problematicidad de la condición humana, sino de su negatividad, presentada en las dos últimas obras como una falta de humanidad activa, voluntaria y consciente.

La ambigua actuación del pueblo del Auto da barca de Camiri se oscurece, así, en la obra $O$ verdugo, en la cual, el héroe, otro posible 
alter ego del Che Guevara, es inicialmente defendido por el pueblo, que pretende salvar al posible redentor de la pena de muerte. Esa tentativa de rebelión popular es sofocada por los poderes locales que, apelando a su avaricia, deciden convencer al conjunto de personas reunidas para impedir la ejecución. Así, el pueblo, demostrando cómo las grandes capacidades del ser humano están atrofiadas, decide sustituir al verdugo que se niega a matar al revolucionario, a cambio de la promesa de un dinero que les permitirá alcanzar sus ideales, que, una vez más, nos orientan hacia lo bajo, pues consisten, simplemente, en trabajar y llenarse la barriga (Hilst, 2008: 424).

Casi nadie se salva, por lo tanto, de la crítica feroz dramatizada por la autora en obras que, por su exceso de realidad, acaban por resultar claramente grotescas: si las clases dirigentes son perversas y crueles, la imagen de las clases populares se construye a partir del principio grotesco de la brutalidad, entendida esta como falta de humanidad o, en el más benévolo de los casos, como auténtica estupidez.

La expresión más acabada de esta visión deforme del mundo está presente en A morte do Patriarca, la última obra teatral de la autora, que no presenta una acción dramática, sino una arquitectura teatral subordinada a una perspectiva final de destrucción iconoclasta (Pallottini, 1999: 108), materializada en un violento espectáculo multitudinario.

Una vez más, Hilst recupera el grotesco panorama de la muchedumbre situada en la plaza pública para dar un giro radical a su representación del pueblo: una vez satisfechas las necesidades mencionadas en $O$ verdugo, la turba confusa y desordenada cae en la insatisfacción más radical, pues, como les había advertido el Demonio, que contempla divertido el espectáculo de la masa levantisca, después de pedir comida y de saciar el vientre, solo podía llegar un nuevo tiempo, un tiempo "de nada" (Hilst, 2008: 487).

$\mathrm{Si}$, como sintetiza Kayser, "[1]o grotesco es una estructura. Podríamos definir su naturaleza a partir de una expresión [...]: lo grotesco es el mundo en estado de enajenación" (2010: 309), no hay duda de que es 
exactamente esto lo que podemos observar en esta obra: una miniatura de nuestro mundo que, una vez solventados los problemas relacionados con las necesidades materiales más urgentes se enfrenta $-\mathrm{y}$ nos enfrenta - a una inquietante e insustentable sensación de vacío e insatisfacción. Esto es, el universo que nos resultaba familiar, aquel dominado por la preocupación por el bienestar material de todos los seres humanos, nos revela un fondo extraño e inquietante, la Nada que se oculta por detrás de ese pobre ideal que apenas se puede centrar en la conquista de esas necesidades básicas.

En una representación típicamente grotesca, ese pueblo decepcionado, inicialmente, solo consigue gruñir y hacer ruido en el exterior de un palacio donde se reúnen los poderosos, pues "l'échec du langage, à la fois ridicule et tragique, est synonyme de grotesque - il est symptomatique de la démultiplication à l'infini des mêmes personnages débitant les mêmes phrases_-" (Wellnitz, 2004: 25) o, en este caso radical, los mismos sonidos inarticulados. Al final —y no podía ser de otro modo, esa turba, esa muchedumbre confusa y desordenada acabará canalizando su energía, impetuosa e irracional, hacia la violencia, representando una risible revolución contra la autoridad.

La radicalidad de la propuesta grotescamente satírica de la autora brasileña, con sus bailes de máscaras, llega a su punto culminante en esta obra, en la que asistimos a la discusión entre los representantes últimos de la autoridad espiritual: el Demonio, el Papa, un Cardenal, Monseñor y varios Ángeles, que discuten diversas doctrinas, religiosas y políticas, revisando y criticando los postulados de Jesús, Mao, Marx o Lenin.

Este examen dialéctico de la Historia de Occidente revela las contradicciones, aporías y zonas de sombra de los principios representados por las tres últimas figuras, hasta que el Papa, incapaz, igualmente, de ilusionar a las masas y de controlar la situación, es asesinado por una ráfaga de metralleta, proveniente de la plaza en la que el pueblo protesta.

Se trata del desenlace perfecto del nihilismo implícito en la obra $\mathrm{y}$, sin duda, construido en las diversas piezas de un modo concienzudo y gradual: cuando ese pueblo descubre que los grandes dogmas y verdades 
universales ya no funcionan, que no les ofrecen ningún consuelo, la única solución es la extinción definitiva de los mismos a través, no de la palabra, sino de la violencia. Así, en un mundo en que todo ha sido dicho (Hilst, 2008: 449), el rebaño dócil de las otras obras se muestra, gracias a la influencia del Demonio, tan definitivamente sombrío cuan negativamente oscuro.

Una vez más, por lo tanto, el pueblo se nos muestra apenas como títere, como personaje manipulable, sin voz en este grotesco teatro del mundo, en el cual es reducido a mera sombra. Durante el desarrollo de la acción dramática, el pueblo es situado fuera de escena y fuera del escenario donde las altas instancias debaten su destino, reduciéndose su presencia a unos espacios sonoros que evocan una clara relación con el Auto da barca de Camiri, a través de intervenciones limitadas al fragor que los protagonistas oyen dentro de la sala y, posteriormente, a las ráfagas de sus metralletas.

La atmósfera alucinada creada por la sombría y paradójica presencia in absentia del pueblo, primero deslumbrado y después desengañado por el aparato del poder, es el retrato definitivo del fracaso del ser humano en el teatro hilstiano, cuya brutalidad contra la autoridad nos demuestra, de un modo grotescamente desencantado, que estamos presenciando el colapso social definitivo, a pesar de que el personaje del Demonio intente restarle importancia, afirmando que el mundo se acabó ya millones de veces y mencionando vagamente unos estudios escatológicos (Hilst, 2008: 442) presentes en la sala donde se sitúa la acción.

La obra es dominada, por lo tanto, por esta figura del Demonio que, a pesar del carácter apocalíptico de la obra, se aproxima más a la caracterización medieval de esta figura que al melancólico y terrorífico diablo romántico, pues sus actitudes parecen evocar la disposición ligera y desenfadada típica de la visión medieval, en la cual "el diablo es un despreocupado portavoz ambivalente de opiniones no oficiales, de la santidad al revés [...]. No tiene ningún rasgo terrorífico ni extraño" (Bajtín, 2002: 42). 
Sirviéndose, mutatis mutandis, de una técnica semejante a la dominante en el grotesco pictórico, en el que se crea "un monde vertical entièrement défini par le jeu graphique, sans épaisseur ni poids" (Chastel, 1988: 25), la coincidencia de la tierra y el infierno, lugares igualmente distantes del cielo, es presentada con naturalidad en la obra de Hilst. En ese espacio caracterizado por la desrealización, el retrato del Demonio es construido a partir de principios rectores como la agudeza y la jovialidad: se trata de un ser dialogante y atractivo, un sofista, como el diablo con quien habló San Antonio o Lutero (Martínez Teixeiro, 2009: 184). Pero también un ser sarcástico y a veces eufórico, del que puede ser paradigma el corporizado en el momento de la muerte del Papa, al conmemorar el inicio de un nuevo ciclo histórico en un mundo del cual los dioses, una vez más, han desertado, pues, según él afirma, en un nuevo proceso de rebajamiento grotesco en que lo sagrado es reinterpretado en el plano material, Dios reposa y no quiere regresar (Hilst, 2008: 444).

\section{LA IMPORTANCIA DE LAS MÚLTIPLES DECLINACIO- NES DE LO GROTESCO EN EL TEATRO HILSTIANO}

Sin descubrir caminos positivos u ofrecer respuestas o soluciones, la propuesta teatral de Hilda Hilst nos deja apenas la consciencia del absurdo de la opresión de los totalitarismos surgidos durante el siglo XX, sea cual fuere su naturaleza - religiosa, estatal o científico-futurista-, pues, si "las creaciones grotescas son un juego con lo absurdo" (Kayser, 2010: 314), en este caso, además nos pretenden alertar respecto al riesgo de deshumanización del hombre (Vincenzo, 1992: 64), derivado de la pérdida de libertad intelectual, moral y espiritual.

Con este fin, como hemos pretendido demostrar en estas digresivas y descriptivas páginas, las obras dramáticas hilstianas funcionan como un conjunto, como una expresiva y grotesca ilustración de un fenómeno típicamente latinoamericano. De hecho, el contenido y la naturaleza de los textos dramáticos producidos en la misma época en otros países 
de Sudamérica permite identificar algunos paralelismos, pues, si la coincidencia en el tiempo de ciertos regímenes dictatoriales no legitima la búsqueda de una uniformidad temática, sí existen ciertas semejanzas al estudiar la dramaturgia latinoamericana como un conjunto de dramaturgias nacionales, como han señalado, con distanciada lucidez analítica, no pocos de los protagonistas del teatro de aquellos tiempos y lugares:

En los años finales de la década de los sesenta las gentes de teatro en Latinoamérica creíamos en una expresión dramática que interpretaba una revolución utópica. Frente a ella, la realidad nos golpeó sin retórica alguna. Cayeron las más antiguas democracias del continente, Chile y Uruguay. Argentina se sumió en un genocidio que nadie ha logrado todavía explicar, atendiendo a su alto desarrollo cultural y social. Algo parecido ocurre en Brasil, mientras Colombia y los países de América Central ven agudizarse las contradicciones y consolidarse la injusticia (Giménez, 1988: 61).

La propuesta teatral de Hilda Hilst sería, así, una grotesca expresión de esa experiencia de la desilusión vivida por los intelectuales sudamericanos, pero, también, de una vivencia típicamente característica del siglo XX, provocada por el resurgimiento generalizado e inesperado del cesarismo y por la revelación de la atrocidad humana en esa tierra devastada en que se convirtió el mundo después de las catástrofes de la Primera y la Segunda Guerra Mundial y del fascismo y el estalinismo.

Sirviéndose del pensare raccontando de Italo Calvino y obedeciendo a la escritura nocturna de Ernesto Sábato, Hilst consiguió condensar esa terrible fase del crepúsculo de la utopía, a través de una afinada técnica de contraste entre la sublimación de los protagonistas y el lúcido recurso a las múltiples posibilidades y declinaciones de lo grotesco, para retratar el deforme e incomprensible panorama social contemporáneo. Un panorama social en el cual, gracias a la dimensión 
carnavalesca, provocadora, delirante, obscena y/o siniestra de lo grotesco presente en estas obras, que oscilan entre el humor absurdo y el llanto macabro, conseguimos comprender la naturaleza intrínsecamente grotesca de un mundo en el cual descubrimos que lo problemático, lo imposible, inesperada e incomprensiblemente, es el heroísmo.

\section{REFERENCIAS BIBLIOGRÁFICAS}

BAJTÍN, M. (2002). La cultura popular en la Edad Media y en el Renacimiento. El contexto de François Rabelais. Madrid: Alianza Editorial.

COSTA, M. C. \& SOUSA JUNIOR, W. (2018). "Censorship on the Brazilian scene: the 'distribution of the sensible' and art as a political force". En Theatre and Dictatorship in the Luso-Hispanic World, D. Santos Sánchez (ed.), 58-70. London: Routledge.

CHASTEL, A. (1988). La grottesque. Essai sur l'ornement sans nome. Paris: Le Promeneur / Quai Voltaire.

FOUCAULT, M. (1994). Dits et écrits 1954-1988. Paris: Gallimard.

GARCÍA-PASCUAL, R. (2012). "Protocolo de valoración del código de comunicación grotesco en las creadoras teatrales (siglos XX y XXI): teoría y práctica escénica". Signa. Revista de la Asociación Española de Semiótica 21, 13-53 (también en http://revistas.uned. es/index.php/signa/article/view/6299 [20/12/2017]).

GIMÉNEZ, C. (1988). “Festivales, ¿para qué?, ¿para quiénes?”. En Escenarios de dos mundos. Inventario teatral de Iberoamérica I, M. Pérez Coterillo (ed.), 60-63. Madrid: Centro de Documentación Teatral.

HILST, H. (2008). Teatro completo. São Paulo: Editora Globo, 2. ${ }^{\text {a }}$ ed.

KAYSER, W. (2010). Lo grotesco. Su realización en literatura y pintura. Madrid: La Balsa de la Medusa.

KOTT, J. (1978). Shakespeare, notre contemporain. Paris: Payot.

KRISTEVA, J. (1982). Powers of Horror. An Essay on Abjection. New 
York: Columbia University Press.

LAWSON, J. H. (1995). Teoría y técnica de la escritura de obras teatrales.

Madrid: Publicaciones de la Asociación de Escritores de Escena de España.

MARIANO, M. do R. (2005). "Algumas Reflexões sobre o Grotesco e Variações em B Maior: Beckett, Baudelaire, Brueghel, Bosch”. En O Grotesco, C. Reis (coord.), 55-66. Coimbra: Centro de Literatura Portuguesa da Universidade de Coimbra.

MARTÍNEZ TEIXEIRO, A. (2009). O herói incómodo. Utopia e pessimismo no teatro de Hilda Hilst. Coruña: Biblioteca-Arquivo Teatral 'Francisco Pillado Mayor' de A Universidade da Coruña.

MEINDL, D. (1996). American Fiction and the Metaphysics of the Grotesque. Columbia: University of Missouri Press. (2005). "The Grotesque: Concepts and Illustrations". En O Grotesco, C. Reis (coord.), 7-22. Coimbra: Centro de Literatura Portuguesa da Universidade de Coimbra.

PALlOTTINI, R. (1999). "Do teatro". Cadernos de literatura brasileira $8,97-113$.

PAVIS, P. (1998). Diccionario del teatro. Dramaturgia, estética, semiología. Barcelona: Paidós Comunicación.

PRADO, D. de A. (2001). O teatro brasileiro moderno. São Paulo: Perspectiva.

VINCENZO, E. C. de (1992). Um teatro da mulher. Dramaturgia feminina no palco brasileiro contemporâneo. São Paulo: Perspectiva / Editora da Universidade de São Paulo.

WELLNITZ, P. (2004). "Le grotesque littéraire: simple style ou genre à part entière?”. En Le grotesque: théorie, généalogie, figures, I. Ost, P. Piret et L. Van Eynde (eds.), 15-27. Bruxelles: Publications des Facultés Universitaires Saint-Louis.

Recibido el 27 de marzo de 2018.

Aceptado el 12 de junio de 2018. 
